\title{
Ç̧̇̌̆́NEME KASLARINDAKİ HİPERTROFİ TEDAVİSİNDE UYGULANAN KONSERVATİF YÖNTEMİN ULTRASONOGRAFİ KULLANARAK DEĞERLENDİRİLMESİ
}

\section{THE EVALUATION OF CONSERVATIVE METHOD APPLIED IN THE TREATMENT OF HYPERTROPHY OF MASTICATORY MUSCLES VIA USING ULTRASONOGRAPHY}

\author{
Arş. Gör. Meltem ÖZDEN YÜCE* \\ Prof. Dr. Esin ALPÖZ**
}

\author{
Doç. Dr. Banu ÖZVERI KOYUNCU* \\ Prof. Dr. Gülcan COŞKUN AKAR ${ }^{* * *}$
}

Makale Kodu/Article code: 4788

Makale Gönderilme tarihi: 23.12 .2020

Kabul Tarihi: 16.06.2021

DOI: $10.17567 /$ ataunidfd.953287
Meltem Özden Yüce: ORCID ID: 0000-0002-7088-9701 Banu Özveri Koyuncu: ORCID ID: 0000-0002-0074-0055 Esin Alpöz: ORCID ID: 0000-0001-6654-9715

Gülcan Coşkun Akar: ORCID ID: 0000-0002-9343-9228

\section{öz}

Amaç: Bu çalışmanın amacı, çift taraflı masseter kas hipertrofisi yakınması ile diş hekimliği fakültesine başvuran hastaların klinik değerlendirmeleri yapıldıktan sonra planlanan konservatif tedavi etkinliğinin klinik ve ultrasonografik olarak değerlendirilmesidir. Gereç ve Yöntem: Masseter kas hipertrofisi yakınması olan 25 hasta çalışma grubuna; masseter hipertrofisi olmayan 25 hasta kontrol grubuna dahil edilmiştir. Çalışma grubuna dahil edilen hastaların tedavisi konservatif yöntem ile yapılmışır. Olguların üç ay boyunca düzenli kontrollerle izlemi yapılmış, tedavi başında ve üçüncü ayın sonunda ultrasonografik ve klinik değerlendirmeler tekrarlanmıştır.

Bulgular: Çalışma ve kontrol grubundaki hastalarda, masseter kasın dinlenme ve kontraksiyon değerlerinin istatistiksel analiz sonuçlarına göre; masseter kasının plak tedavisinin 3. ayındaki ölçümlerinde, tedavi öncesine göre kas kalınlığının istatistiksel olarak anlamlı şekilde değiştiği gözlenmiștir. VAS değerlendirmesinde ise Wilcoxon signed ranks testi kullanılmıștır. Hastaların tedavi öncesi ve sonrası VAS değerleri incelendiğinde tedavi öncesi VAS skoru medyanı $6(\mathrm{~min}=2 ;$ mak $=8)$ iken tedavi sonrası VAS skoru medyanı 2 ( $\min =0 ;$ mak=6) bulunmuştur.Tedavi sonrası VAS değerlerindeki azalma istatistiksel olarak anlamlı bulunmuştur $(p<0,001)$.

Sonuç: Stabilizasyon tedavisinin oklüzal dinamikler üzerinde etkili olarak ağrı yakınmasında azalmaya neden olduğu klinik olarak kanıtlanmıştır. Ancak, hipertrofi hastalarına uygulanan stabilizasyon tedavisinin başarısını ultrasonografik olarak değerlendirmek için daha geniş popülasyonlarda yapılacak çalışmalara intiyaç duyulmaktadır.

Anahtar kelimeler: Çiğneme Kasları, Hipertrofi, Konservatif Tedavi, Ultrasonografi

\section{ABSTRACT}

Aim: The aim of this study is to evaluate the efficacy of conservative treatment both clinically and ultrasonographically in the patients who referred to the dentistry faculty with bilateral masseter muscle hypertrophy.

Materials and Methods: In this study; 25 patients with masseter muscle hypertrophy were included in the study group; 25 patients without masseter hypertrophy were included in the control group. The treatment of the patients included in the study group was carried out with conservative method. The patients were followed up regularly for three months and ultrasonographic and clinical evaluations were repeated at the beginning of the treatment and at the end of the third month.

Results: According to the statistical analysis results for the resting and contraction values of the masseter muscle in the study and control groups; the thickness of masseter muscle at the 3rd month of the occlusal splint therapy changed significantly compared to before treatment. Wilcoxon signed ranks test was used in the evaluation of VAS. When the VAS scores of the patients before and after treatment were examined, the median VAS score before treatment was $6(\min =2 ; \max =8)$, while the median VAS score after treatment was found to be $2(\min =0 ; \max =6)$. The decrease in VAS values after treatment was found to be statistically significant $(p<0.001)$.

Conclusion: It has been clinically proven that stabilization therapy has an effect on the occlusal dynamics and reduces pain. However, studies with larger populations are needed to evaluate the success of stabilization therapy applied to hypertrophy patients ultrasonographically.

Keywords: Masticatory Muscles, Hypertrophy, Conservative Treatment, Ultrasonography

\footnotetext{
* Ege Üniversitesi Diş Hekimliği Fakültesi, Ağız, Diş ve Çene Cerrahisi Anabilim Dalı, İzmir.

** Ege Üniversitesi Diş Hekimliği Fakültesi, Ağız, Diş ve Çene Radyolojisi Anabilim Dalı, İzmir.

*** Ege Üniversitesi Diș Hekimliği Fakültesi, Protetik Diș Tedavisi Anabilim Dalı, İzmir.
}

Kaynakça Bilgisi: Özden Yüce M, Özveri Koyuncu B, Alpöz E, Coskun Akar G. Çiğneme kaslarındaki hipertrofi tedavisinde uygulanan konservatif yöntemin ultrasonografi kullanarak değerlendirilmesi . Atatürk Üniv Diş Hek Fak Derg 2021; 31: 606-12.

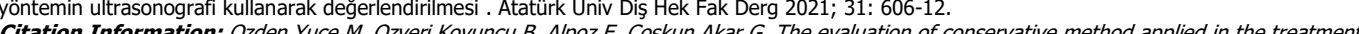

Citation Information: Ozden Yuce M, Ozveri Koyuncu B, Alpoz E, Coskun Akar G. The evaluation of conseria
of hypertrophy of masticatory muscles via using ultrasonography. J Dent Fac Atatürk Uni 2021; 31: 606-12 


\section{GİRIŞ}

Çiğneme kaslarının hipertrofisinde temporal, masseter ve pterygoid kaslar etkilenmekte olup; sıklıkla masseter hipertrofisi şeklinde gözlenmektedir. Tek veya çift taraflı olabilen bu durumun etiyolojisi hakkında herhangi bir ortak görüş bulunmamakla birli kte literatürde organik ve inorganik etkenler gösterilmektedir.1,2 Organik etkenler arasında diş kaybına bağlı tek taraflı çiğneme, konjenital arteriovenöz fıstül, temporomandibuler eklem disfonksiyonu ve lokal distoniler gösterilirken, inorganik etkenler arasında devamlı sakız çiğneme, gece veya gündüz diş sıkma, strese bağlı parafonksiyonel çene hareketleri yer almaktadır. ${ }^{3}$ İnorganik nedenler arasında gösterilen, diş sıkma ve gıcırdatma alışkanlığının, kasta aşıı kullanıma bağlı hipertrofi oluşturduğu belirtilmektedir., ${ }^{1,2}$ Bruksizm üzerine 1900'lü yıllardan günümüze kadar yapılan birçok çalışma olmasına rağmen bruksizmin etiyolojisi ve patolojisi henüz açıklık kazanmamıştır. ${ }^{4}$ dolayısıyla efektif bir tedavi uygulamak çoğu zaman zor olmaktadır. Bu noktada diş hekiminin temel görevi farmakolojik, psikolojik ve dental açıdan hastanın şikayetlerini azaltmak ve çene-yüz bölgesindeki yapıları gelişebilecek zararlardan korumaktır. ${ }^{5}$

Masseter hipertrofisi tedavisi, fiziksel ve psikolojik düzensizlikler ile etiyolojik faktörleri ortadan kaldırmayı amaçlayan iyi düzenlenmiş bir tedavi programı ile mümkündür. İki tip tedavi seçeneği vardır; birincisi, hasta eğitimi, fizik tedavi, farmakolojik tedavi, oklüzal splint tedavisi gibi geriye dönüşümü olan yöntemleri içeren konservatif yaklaşımlardır; ikincisi ise cerrahi yöntemler, oklüzal aşındırma, protetik restorasyon ve ortodontik tedavi gibi geriye dönüşümü olmayan tedavi yöntemleridir. ${ }^{6}$

Cerrahi ve cerrahi olmayan yöntemlerle tedavi edilebilen, sıklıkla ağrının da eşlik ettiği hipertrofiler için, hamilelik, radyoterapi gören olgular, cerrahi kontraendikasyonları gibi bazı durumlarda başka bir seçeneğin kullanılamaması bazen de diğer tedaviler için basamak oluşturması amacıyla ağız içi plak uygulamaları tedavide ilk seçenek olarak karşımıza çıkmaktadır. ${ }^{7-11}$

Çalışmamızda "çiğneme kaslarındaki hipertrofi vakalarında uygulanan konservatif tedavi yöntemi ile tedavi öncesine göre masseter kas kalınlığı ve ağrı semptomunda azalma gözlenir" hipotezi test edilmiştir. Bu amaçla çalışmamızda Diş Hekimliği Fakültesi Protetik Diş Tedavisi A.D ve Ağız, Diş ve Çene Cerrahisi A.D ' na tek ve/veya çift taraflı masseter kas hipertrofisi yakınması ile başvuran hastaların klinik değerlendirmeleri yapıldıktan sonra planlanan konservatif tedavi etkinliği Ağız, Diş ve Çene Radyolojisi A.D `nda ultrasonografik olarak değerlendirildi.

\section{GEREÇ VE YÖNTEM}

Çalışmaya 2017-2019 yılları arasında Diş Hekimliği Fakültesi'ne masseter kas bölgesindeki hipertrofi ve ağrı yakınması ile başvuran 25 kişi (18 kadın, 7 erkek, yaş aralığı 21-55 olup yaş ortalaması 33.44) ile kontrol grubu olarak hipertrofi yakınması olmayan 25 kişi (14 kadın, 11 erkek, yaş aralığı 23-28 olup, yaş ortalaması 26.00) olmak üzere toplam 50 kişi dahil edildi. Çalışma için gerekli etik onay, Tıp Fakültesi Klinik Araştırmalar Etik kurulundan alındı. (14.01.2016 karar numarası: 15-9/14).18 yaş üzeri; alt-üst diş dizilerinde eksik dişi, süt dişi, gömük dişi (8 numaralı dişler hariç) bulunmayan; masseter bölgesinde şişlik yakınması bulunan; ultrason incelemesini engelleyecek herhangi bir hastalığı bulunmayan; klinik ve radyolojik olarak herhangi bir odontojenik problemi bulunmayan; onam formunu imzalayarak çalışmaya katılmaya gönüllü olan hastalar çalışmaya dahil edildi. İlgili bölgede şişlik yaratabilecek abse, dental kökenli, tükürük bezi kökenli, malign/ benign lezyonlar, lenfadenopati kökenli ve lipom benzeri lezyonlara sahip olan; travma hikayesi bulunan; aktif kabakulak öyküsü olan; ultrason alanında açık yarası olan; mandibular hipertrofisi olan; ve/veya iletişim problemi olan hastalar çalışmaya dahil edilmedi. Kontrol grubunda ise; 18 yaş üzeri, alt-üst diş dizilerinde eksik dişi, süt dişi, gömük dişi (8 numa- ralı dişler hariç) bulunmayan; masseter bölgesinde şişlik yakınması olmayan; dişler, çeneler ve yüz bölge- sinde ağrı yakınması olmayan; ağız açmada kısıtılık yakınması bulunmayan; ultrason incelemesini engelle- yecek herhangi bir hastalığı bulunmayan bireyler dahil edildi.

E.Ü Diş Hekimliği Fakültesi Ağız, Diş ve Çene Radyolojisi Ana Bilim Dalı'nda hastaların rutin tanı ve tedavi planlaması amaçlı panoramik röntgen cihazı (Kodak9000 3D Trophy France) ile alınan radyografik tetkikler yardımı ile odontojenik kökenli asimetri varlığı elimine edildi. Hastaların klinik, US değerlendirmeleri ve özbildirim değerlendirilmeleri, hazırlanan formlara kaydedildi. Hastaların sistemik rahatsızlığı, ağrının derecesi, ailede hipertrofi varlığı ve süresi, parafonksiyonel alışkanlıkları sorgulandı. Kronik ağrının şiddetinin değerlendirilmesinde kullanılan Vizuel Analog Skala (VAS) ağrı ölçüm metodu ile hastaların subjektif 
ağrı değerlendirmesi yapıldı. Hastalar tedavi öncesi ve sonrasında hissettikleri ağrının şiddetini 0 ile 10 arasında numaralandırmaları konusunda bilgilendirildi. Klinik değerlendirmede ise diş aşınma paternleri kaydedildi.

Çalışmaya alınan hastalara yapılacak tedavi hakkında bilgi verilerek, hastalara aydınlatılmış hasta onam formu imzalatıldı. Klinik değerlendirme sonrasında işlem hakkında bilgilendirilen hastaların ultrasonografik incelemeleri fakültemizde bulunan Hitachi Aloka F37 Diagnostic Ultrasound System (Hitachi Aloka Medical Ltd., Tokyo, Japan) cihazı kullanılarak gerçekleştirildi. Ultrasonografik tetkikler sırasında ilk olarak çeneler istirahat konumunda, daha sonra çene kontraksiyonda iken üç kayıt yapıldı. Ultrasonografik ölçümlerin ortalaması alınarak kaydedildi. Ölçümler tek bir Ağız, Diş ve Çene Radyolojisi uzmanı tarafından gerçekleştirildi.

Çalışmaya alınan her hasta ve kontrol grubundaki olgulara, uyku süresince (yaklaşık 8 saat) kullanım sonrasında alt-üst dişler arasındaki değim alanlarını belirlemek için kullanılan $0.1 \mathrm{~mm}$ kalınlığında ve $125 \mathrm{~mm}$ çapında, kırmızı renkli polivinil klorür plaklar (BruxCheckerß, SheuDental GMBH, Germany) uygulandı (Resim 1). Olgulardan uyku süresince kullan- malarını takiben plağı teslim etmeleri istendi (Resim 2). Kırmızı plaklar üzerindeki aşınma izleri Onodera ve ark. ${ }^{12}$ çalışmasında yer alan, bruksizme dayalı aşındırma modeli ile görselleştirilen oklüzal şemaya göre değerlendirildi (Resim 3).

Ayrıca, çalışma grubundan elde edilen alçı modeller plak basma makinasına (Biostar, SheuDental GMBH, Germany) yerleştirilerek üretici firmanın önerilerinde belirtilen program kullanılarak, $1 \mathrm{~mm}$ kalınlığında ve $125 \mathrm{~mm}$ çapında şeffaf plaklar hazırlandı. Uyum kontrollerini takiben, hasta yarı yatay pozisyonda iken kapanış kontrolleri yapılarak (Resim 4) uyku süresince kullanımları (yaklaşık 8 saat) için hastalara teslim edildi. Ultrasonografik ölçümler hastalara splint uygulamasından önce ve plak kullanımını takiben 3. ay sonunda yapıldı (Resim 5).

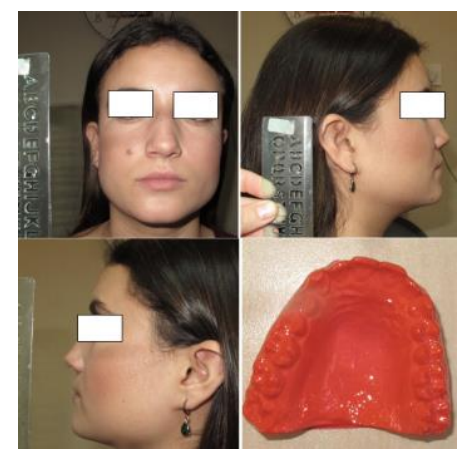

Resim 1: Çift taraflı masseter hipertrofisi ve ağrı şikayeti bulunan kadın hastanın ekstraoral görüntüsü ve hastaya uygulanan kırmızı plak.

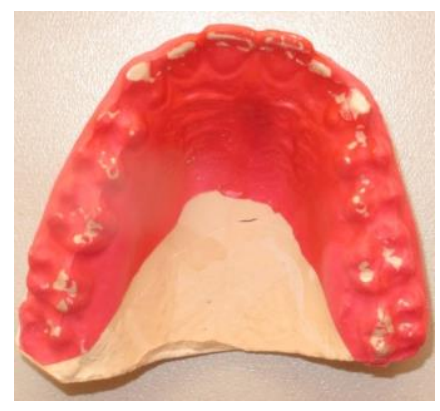

Resim 2. Olgunun uyku süresince kullanım sonrası kırmızı plağın görüntüsü; plak üzerinde beyaz olarak oluşan alanlar alt-üst dizisi arasındaki fizyolojik olmayan dinamik değim alanlarını göstermektedir.

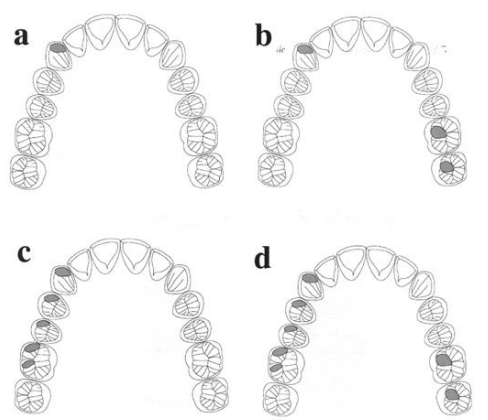

Resim 3. Bruksizme bağlı okluzal aşınma paterni a. Kanin baskın aşınma, b. Kanin baskın + mediotruzyon aşınma, c. Grup aşınma, d. Grup + mediotruzyon aşınma

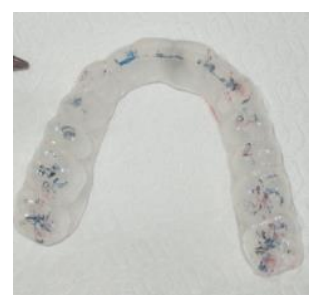

Resim 4. Vakaya ait kapanış uyumu yapılmış şeffaf plak 

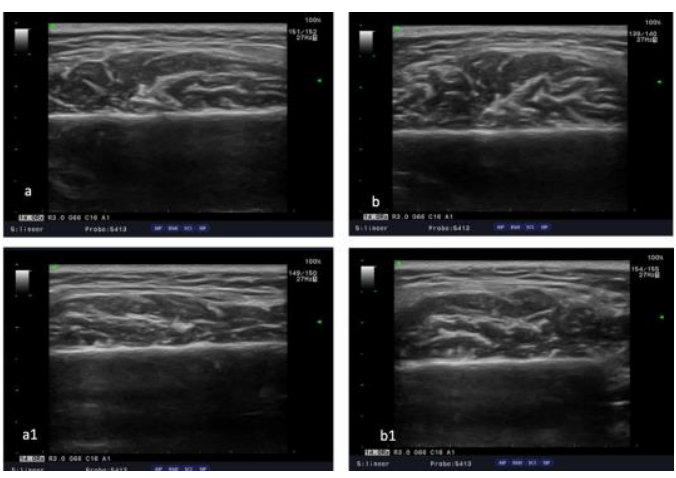

Resim 5. Hastaların splint uygulamasından önce ve plak kullanımını takiben 3 . ay sonunda yapılan ultrasonografik ölçümleri a. hastanın dinlenme pozisyonunda başlangıç görüntüsü,

b. hastanın kontraksiyon pozisyonunda başlangıç görüntüsü, a1. hastanın dinlenme pozisyonunda tedavi sonrası görüntüsü, b1. hastanın kontraksiyon pozisyonunda tedavi sonrası görüntüsü

\section{İstatistiksel Analiz}

Verilerin tanımlayıcı istatistikleri; ortalama, standart sapma, medyan, minimum, maksimum, frekans ve yüzde değerleri olarak verilmiştir. Nicel verilerin normallik varsayımı Shapiro-Wilk testi ile kontrol edilmiştir. Normal dağılım gösteren değişkenler için Bağımlı örneklem t-testi kullanılırken normallik varsayımını sağlamayan değişkenler için Wilcoxon signed-rank testi kullanılmıştır. Tedavi öncesi ve sonrası arasında, kasın fibriler yapısında fark olup olmadığı Mc-Nemar testiyle incelenmiştir.

İstatistiksel analizler IBM SPSS Statistics 25.0 (IBM SPSS Statistics for Windows, Version 25.0. Armonk, NY: IBM Corp.) paket programı kullanılarak yapılmışır. Tüm analizlerde anlamllık düzeyi 0,05 olarak belirlenmiştir.

\section{BULGULAR}

Çalışma grubundaki hastaların 18'i kadın, 7'si erkekti. Hastaların yaş aralığı 21-55 olup yaş ortalaması 33,4 $\pm 2,36$ iken; kontrol grubundaki bireylerin ise ise $14^{\prime} \mathrm{i}$ kadın, $11^{\prime} \mathrm{i}$ erkek olup, yaş ortalaması $26,0 \pm 1,8$ olarak hesaplandı (Tablo 1 ).

Tablo 1. Çalışma ve Kontrol Gruplarının Cinsiyete göre Yaş Dağılımları

\begin{tabular}{lccc}
\hline & & $\begin{array}{l}\text { Erkek } \\
\text { n (\%) }\end{array}$ & $\begin{array}{l}\text { Kadın } \\
\mathbf{n}(\%)\end{array}$ \\
\hline Çalışma Grubu & & & \\
Yaş (yıl) & 25 & $0(0)$ & $3(16,7)$ \\
& $25-40$ & $3(42,9)$ & $9(50,0)$ \\
Kontrol Grubu & $>40$ & $4(57,1)$ & $6(33,3)$ \\
Yaş (yıl) & $<25$ & $7(63,6)$ & $8(57,1)$ \\
\hline
\end{tabular}

Çalışma grubunda yer alan hastaların parafonksiyonel alışkanlıkları değerlendirildiğinde 2 hastada infantil yutkunma, 2 hastada ise tırnak yeme alışkanlığı bulunduğu belirlendi. Hastalar sistemik hastalık varlığı yönünden incelendiğinde 2 hastada diyabetes mellitus, 1 hastada vertigo, 1 hastada multipl skleroz, 3 hastada hipertansiyon olduğu belirlendi. Ek olarak hastaların hiçbirinde ailesel hipertrofi öyküsü olmadığı saptandı. Masseter hipertrofisi süresi değerlendirildiğinde ise sürenin 1-40 yıl arasında değiştiği, ortalama değerinin ise $5,56 \pm 7,48$ yıl olduğu tespit edildi.

Kırmızı plaklar üzerindeki bruksizme bağlı okluzal aşınma paternleri incelendiğinde; hastaların $\% 8$ 'inde $(n=2)$ 'Kanin baskın + mediotruzyon aşınma', $\% 48$ 'inde $(n=12)$ 'Grup aşınma' ve \%44'ünde ( $n=11)$ 'Grup+mediotruzyon aşınma' paternleri görüldü. Ayrıca kontrol grubundaki hastaların \%60'ının $(n=15)$ 'Kanin baskın aşınma' ve \%40'ının $(n=10)$ 'Kanin baskın + mediotruzyon aşınma' paternine sahip olduğu görüldü.

Tablo 2. Tedavi öncesi ve sonrası Masseter kasının Dinlenme $(R)$ ve Kontraksiyon $(K)$ değerleri

\begin{tabular}{|c|c|c|c|c|}
\hline & & $\begin{array}{l}\text { Başlangıç (cm) } \\
\text { Ort } \pm \text { SS }\end{array}$ & $\begin{array}{l}\text { Bitiş (cm) } \\
\text { Ort } \pm S S\end{array}$ & p değeri \\
\hline \multirow{4}{*}{ Çalışma Grubu } & SAĞ R & $1,16 \pm 0,21$ & $1,07 \pm 0,21$ & $<0,001$ \\
\hline & SAĞ K & $1,52 \pm 0,22$ & $1,42 \pm 0,22$ & $<0,001$ \\
\hline & SOL R & $1,14 \pm 0,18$ & $1,08 \pm 0,19$ & 0,001 \\
\hline & SOL K & $1,50 \pm 0,32$ & $1,40 \pm 0,26$ & 0,006 \\
\hline \multirow{4}{*}{ Kontrol Grubu } & SAĞ R & $1,07 \pm 0,15$ & & \\
\hline & SAĞ K & $1,40 \pm 0,17$ & & \\
\hline & SOL R & $1,06 \pm 0,23$ & & \\
\hline & SOL K & $1,36 \pm 0,19$ & & \\
\hline
\end{tabular}

SS: Standart Sapma

Hastaların masseter kaslarının, tedavinin hemen öncesinde ve tedavinin 3. ayında ultrasonografik olarak incelendi. Çalışma ve kontrol grubundaki hastalarda, masseter kasın dinlenme ve kontraksiyon değerleri için özet istatistikler ve istatistiksel analiz sonuçları Tablo 2'de verilmiştir. Masseter kasının plak tedavisinin 3. ayındaki ölçümlerinde, tedavi öncesine göre kas kalınlığının istatistiksel olarak anlamlı şekilde değiştiği gözlendi (Tablo 2). Ultrasonografik inceleme sırasında her iki ölçüm sırasında kaslarda ödem, atrofi veya kitle bulgusu saptanmadı. Kaslarda boyut değişikliği dışında ekil veya eko değişikliği izlenmedi.

Kasların fibriler yapısı ekojenik bantların görünümüne göre üç tipte incelendi. Tip1'de ince lineer ekojen bantlar, Tip 2'de hipertrofik görünüm ve düzensiz bant yapısı ve Tip 3'te bant yapısından belirgin azalma ve incelme olarak değerlendirildi. 3 aylık plak kullanım sonrasında kasın fibriler yapısında istatistiksel

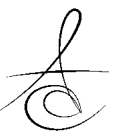


olarak anlamlı bir değişiklik olmadığı tespit edildi ( $p>0,05)$.

VAS değerlendirmesinde ise Wilcoxon signed ranks testi kullanıldı. Hastaların tedavi öncesi ve sonrası VAS değerleri incelendiğinde tedavi öncesi VAS skoru medyanı $6(\min =2 ; \operatorname{mak}=8)$ iken tedavi sonrası VAS skoru medyanı 2 ( $\min =0 ; \operatorname{mak}=6)$ bulundu. Tedavi sonrası VAS değerlerindeki azalma istatistiksel olarak anlamlı bulundu. $(p<0,001)$.

\section{TARTIŞMA}

Temporomandibular eklem (TME); çiğneme, konuşma, yutkunma ve ayrıca tat ve nefes alma gibi önemli fonksiyonları olan; çiğneme kasları, baş ve boyun kasları, ligamanlar, diş, yanak, dudak ve tükrük bezlerinden oluşan çiğneme sisteminin bir parçasıdır.6,13 Temporomandibular hastalıklar ise sadece TME ve çiğneme kaslarından kaynaklanan problemleri içermeyen; aynı zamanda çiğneme sisteminin fonksiyon bozukluklarının tümünü kapsayan hastalıklardır. ${ }^{14} \mathrm{Tem}-$ poromandibuler eklem bozukluğu olan hastaların çoğunda eklem ve kas semptomları sıklıkla birlikte görülmektedir ve eklemin bu kompleks yapısından dolayı hastanın dikkatli bir şekilde değerlendirilmesi ve doğru tanıyı koyarak buna göre tedaviyi yönlendirebilmek önem kazanmaktadır. 15,16

Çiğneme kaslarına ait fonksiyon bozuklukları, hastaların günlük hayatını olumsuz yönde etkileyen; çiğneme, konuşma, yutkunma gibi fonksiyonel hareketlerde kısıtlıklık ve fonksiyon sırasında ve/veya iştirahat sırasında ağrı semptomlarına neden olan şikayetlerdendir. Hastalığın etiyolojisinin tam olarak bilinmemesi tedavi yaklaşımlarını daha çok kaslardaki hiperaktiviteyi azaltarak ağrı semptomunu kontrol altına almak ve fonksiyonları düzeltmeye yöneltmiştir. ${ }^{17}$

Etiyolojisi multifaktöriyel olan bu hastalığın tedavisi de multidisipliner bir yaklaşım gerektirebilmektedir. Etiyoloji biliniyorsa, bu etiyolojiye yönelik değişik tedavi seçenekleri belirlenebilmektedir. Tedavisi hastaya göre farklılık göstermekle birlikte; konservatif tedaviler non-invaziv, düşük riskli, geri dönülebilir ve başarı oranı yüksek uygulamalar oldukları için öncelikli tedavi yöntemi olarak tercih edilmektedirler.6,18 Literatürde ilk olarak Kingsley tarafından uygulanan oklüzal splintlerin etki mekanizmaları; varolan okluzal durumu değiştirmek, kondil pozisyonunu fizyolojik konuma getirmek, dikey boyutta artış sağlama, rahatsızlığını kavrama (zihinsel farkındalığın gelişmesi) ve plasebo etki olarak sayılabilir. ${ }^{19}$ Okluzal splintlerin parafonksiyonel alışkanlığı olan bireylerde alışkanlıktan kaçınma ve dişlerdeki aşınma, kırılma, mobilite, ağrının azaltılması gibi yararları mevcuttur. ${ }^{13,14,20,21}$ Mevcut çalışmada okluzal splintler, kas hiperaktivitesini tedavi etmek ve ağrı,fonksiyon bozukluğu gibi semptomları ortadan kaldırmak için kullanılmıştır.

Kurita ve arkadaşlarının 22 spesifik temporomandibuler bozukluğu olan 232 hastaya oklüzal splint tedavisi uyguladıkları çalışmalarında, çiğneme kaslarındaki hassasiyet şikayetinde $\% 73$ oranında düzelme tespit etmişlerdir. Benzer olarak, Glaros ve arkadaşları 23 yaptıkları çalışmada; okluzal splintlerin hastalarda eklem ağrıları ve çiğnemeye bağlı gelişen ağrıların azalmasında etkili olabileceğini bildirmişlerdir.2006 yılında Conti ve arkadaşlarının ${ }^{24}$ okluzal splintin etkinliğini değerlendirdikleri çalışmalarında, tedavi öncesi ve sonrası ağrı değişikliğini VAS ile ölçmüşler ve splint tedavisi ile VAS değerlerinde anlamlı azalma tespit ettiklerini bildirmişlerdir. Benzer olarak Wassell ve arkadaşları ${ }^{25}$, stabilizasyon splinti ve kontrol splintinin etkinliğinin değerlendirildiği çalışmalarında VAS ile yapılan değerlendirmeler sonucunda stabilizasyon splinti grubunda VAS değerlerinde istatistiksel olarak anlamlı azalma tespit etmişlerdir. Katsoulis ve arkadaşları $^{26}$ ise, okluzal splintin ağrı üzerinde etkisini değerlendirdikleri çalışmalarında, ağrı değerlendirmesi VAS ile yapılmıs ve tedavi sonunda mastikatör kaslarda rahatlama ve ağrı seviyesinde anlamlı oranda azalma tespit etmişlerdir. Mevcut çalışmada da hastaların plak kullanımı sonrası, kas hiperaktivitesindeki değişiklikler sonucunda hastalardaki ağrı şikâyetinde azalma olduğu tespit edilmiştir. Yapılan tedavi sonrası VAS değerlerindeki azalmanın istatistiksel olarak anlamlı olduğunu belirlenmiştir.

Ultrasonografi (USG) yumuşak dokuların değerlendirilmesinde kullanılan noninvaziv bir görüntüleme tekniğidir. Pekince ve arkadaşlarının masseter kas görüntülemede USG'nin etkinliğini değerlendirdikleri çalışmalarında, USG'nin kasın yapısı ve kas içerisindeki spazm noktalarının lokalizasyonu görüntülemede başarılı bir teknik olduğunu raporlamışlardır. ${ }^{27}$ Masseter kas, sıkma sırasında yüksek aktivite gösterdiği için; kas kalınlığının ölçümü çene kasları fonkisyonunun bir göstergesi olarak kabul edilmektedir. Literatürde kas kalınlığını değerlendirmek için bilgisayarlı tomografi, manyetik rezonans görüntüleme ve USG gibi birçok teknik kullanılmış olmakla birlikte, bu çalışmada hızlı, kolay, basit, tekrarlanabilir olan ve yumuşak doku için nispeten daha ucuz bir görüntüleme yöntemi olan USG tercih edilmiştir. ${ }^{28,29}$ 
Sathasivasubramanian ve arkadaşlar $^{30}$ USG kullanarak, tek taraflı kısmi diş eksikliği bulunan hastaların masseter kas kalınlıklarını ölçtükleri çalışmalarında, kısmi dişsiz taraftaki kas kalınlığının dişli taraftaki kas kalınlığına göre anlamlı derece az olduğunu ve bu farkın tek taraflı çiğneme nedeni ile kasın kullanılmama atrofisi ile ilişkili olduğunu raporlamışlardır. Benzer olarak, Çebi ${ }^{28}$ tek taraflı redüksiyonlu disk deplasmanı tanısı alan 100 hastanın masseter kas kalınlığını USG ile değerlendirdiği çalışmasında, kontraksiyon pozisyonunda sağlıkı taraf ile hasta taraf arasındaki kas kalınlığının istatistiksel olarak farklı olduğunu raporlamış ve bu durumun tek taraflı çiğnemeye bağlı olabileceğini belirtmiştir. Myofasiyal ağrılı 5 hastayı 2 aylık stabilizasyon splinti ile tedavi eden Emshoff ve Bertram ${ }^{31}$ ise çalışmalarında, splint kullanımı öncesi ve sonrası ultrason ile anterior temporal, anterior ve derin masseter, anterior ve posterior digastrik ve sternoklavikulomastoid kas kalınlıklarını incelemişler, splint tedavisi sonrasında özellikle masseter kasında lokal kas kalınlığı ve asimetrisinde azalma saptadıklarını bildirmişlerdir. Çalışmamızda literatürle uyumlu olarak; plak tedavisi öncesi ve sonrası ultrasonografik ölçümler ve değerlendirmeler yapılmış olup, tedavi sonunda tüm hastalarda sağ ve sol masseter kasının kalınlığında istatistiksel olarak anlamlı azalma gözlendiği belirlenmiştir.

Mevcut çalışmada temporomandibular eklem düzensizliği olan bireylerde, masseter kasının internal fibriler yapısı ultrasonografik olarak değerlendirildiğinde literatürle uyumlu şekilde tip 2 paterne sahip olduğu saptanmıştır. Bu paterne ait görünümün hipertrofi hastalarındaki aktin ve miyosin fibrillerinde meydana gelen artıştan kaynaklı olduğu; dolayısıyla masseter kasının ultrasonografik görünümünün hiperaktivite ile uyumlu olduğu belirlenmiştir. Çalışmamızda değerlendirilen hipertrofi olgularında, Aldemir ve ark.nın ${ }^{6}$ çalışmalarına benzer şekilde Tip 3 fibriler yapı saptanmamıştır. Tip 3 paternde izlenen ekojenik bantlardaki azalmanın hatta tamamen ortadan kalkmasının geriatrik popülasyonda gelişen kas atrofisine bağlı gelişebileceği belirtilmektedir. Mevcut çalışma grubuna dahil edilen bireylerin yaş ortalamasının 33.44 olması nedeni ile Tip 3 yapının saptanmamasının literatür ile uyumlu olduğu düşünülmektedir.

Sonuç olarak, TME hastalıklarının tedavisinde hastaların şikayetlerinin ortadan kaldırılmasında konservatif tedavi yaklaşımı, etkili ve ekonomik bir yöntemdir. Çalışmada TME hastalıklarında plak tedavisinin masseter kası üzerine etkilerinin değerlendirilmesinde klinik semptomlara ek olarak, non-invaziv bir yöntem olan ultrasonografi tercih edildi. Ultrasonografik değerlendirmelerde stabilizasyon tedavisinin masseter kasın kalınlığında azalma yarattığı ancak kasın fibriler yapısında herhangi bir anlamlı değişiklik yaratmadığı saptandı. Fibriler yapıda anlamlı bir farklılaşma olmaması tedavinin kasta atrofi, iskemi ve kanlanma bozukluğu yaratmaması şeklinde açıklanabilir. Stabilizasyon tedavisinin oklüzal dinamikler üzerinde etkili olarak ağrı yakınmasında azalmaya neden olduğu klinik olarak kanıtlanmıştır. Ancak hipertrofi hastalarına uygulanan stabilizasyon tedavisinin başarısını ultrasonografik olarak değerlendirmek için daha geniş popülasyonlarda yapılacak çalışmalara intiyaç duyulmaktadır.

\section{Finansal Destek ve Çıkar Catışması}

Bu makale yazarlarından hiçbirinin makalede bahsi geçen konu veya malzemeyle ilgili herhangi bir ilişkisi, bağlantısı veya parasal çıkar durumu söz konusu değildir.

\section{KAYNAKLAR}

1.Gurney CE. Chronic bilateral benign hypertrophy of the masseter muscle. Am J Surg 1947; 73:137-9.

2. Albuquerque $C E$, Prado $R$, Pereira-Stabile $C L$, Filho AM. Conservative treatment of bilateral temporalis muscle hypertrophy in a pregnant woman. J Craniofac Surg 2012; 23:20-2.

3.Yaman Z, Özkal Ş, Göktepe S. Bening Masseter Hipertrofisinin Botulinum Toksin Tip A ile Tedavisi. İ Ü Diş Hek Fak Der 1997; 31:3-6.

4. Kavaklı Y. Polisomnografi ile teşhis edilen uyku bruksizmli hastaların tedavisinde 2 farklı apareyin etkinliğinin değerlendirilmesi. Doktora tezi 2006. Hacettepe Üniversitesi.

5.Mısırlıŏlu M, Yılmaz S, Adışen MZ. Bruksizmin Tanısı, Tedavisi ve Görüntülenmesi Üzerine Yeni Görüşler. A.Ü. Diş Hek Fak Derg 2012; 39:93-102.

6.Aldemir K. Ağrılı TME hastalıklı bireylerde stabilizasyon splint tedavilerinde masseter kasındaki değişikliklerin ultrasonografik incelenmesi. Doktora tezi 2008. Ankara Üniversitesi.

7. Al-Ahmad HT and Al-Qudah MA: The treatment of masseter hypertrophy with botulinum toxin type A. Saudi Med J 2006; 27:397-400.

8.Hakam MM, Beheiry MG and Helmy ES: Surgical management of benign masseteric hypertrophy (B.M.H.). Egypt Dent J 1995; 41:1435-40.

9.Jin Park Y, Woo Jo Y, Bang SI, et al. Radiofrequency volumetric reduction for masseteric hypertrophy. Aesthetic Plast Surg 2007; 31:42-52. 
10. Hashimoto T, Kuroda S, Kamioka H, Mishima K, Sugahara $\mathrm{T}$ and Takano-Yamamoto $\mathrm{T}$. Bimaxillary protrusion with masseter muscle hypertrophy treated with titanium screw anchorage and masseter surgical reduction. Am J Orthod Dentofac Orthop 2009; 135:536-48.

11.Özkan BT, Tabrizi R and Cigerim L. Management of bilateral masseter muscle hypertrophy. J Craniofac Surg 2012; 23:14-6.

12.Onodera K, Kawagoe T, Sasaguri K, ProtacioQuismundo C, Sato S. The use of a bruxchecker in the evaluation of different grinding patterns during sleep bruxism. Cranio 2006; 24:292-9.

13.Ramoğlu S, Ozan O, Aydın M. Temporomandibuler eklem bozukluklarındakonservatif tedavi yaklaşımları: Okluzal splintler. ADO J Clinical Sci 2011; 5:2.

14. Aksüzek Ö, Mumcu E, Ceylan G., Aktaş B, Ünalan F. Temporomandibular Rahatsızıkların Tedavisinde Kullanılan Oklüzal Splintler.İstanbul Üniversitesi Dişhekimliği Fakültesi Dergisi 2009; 43:53-7.

15. Dworkin SF., Huggins KH., LeResche L., Von KorffM., Howard J., Truelove E. Sommers E. Epidemiologyof signs and symptoms in temporomandibulardisorders: clinical signs in cases and controls. J Am Dent Assoc 1990; 120:273-81.

16. Schmitter M., Rammelsberg P., Hassel A. The prevalenceof signs and symptoms of temporomandibulardisorders in very old subjects, J. Oral.Rehabil 2005; 32:467-473.

17. Dworkin SF., LeResche L. Research diagnosticcriteria for temporomandibular disorders: review, criteria, examinations and specifications, critique, J. Craniomandib Disord 1992; 6:301-355.

18. Wahlund K, List $\mathrm{T}$, Larsson B, Treatment of temporomandibular disorders among adoles-cents: A comparison between occlusal appliance, relaxation trainig, and brief information. Acta Odontol Scand 2003; 61: 203-11.

19. McNeill C. History and evoluation of TMD concepts. Oral Surg Oral Med Oral Pathol 1997; 83:51-60.

20. Tekel N, Kahraman S. temporomandibular eklem bozukluklarının tedavisinde oklüzal splintlerin kullanımı. Atatürk Üniv Diş Hek Fak Derg 2006 ;61-9.

21. Bulut AC, Atsu S. Bruksizm Tanı ve Tedavisinde Güncel Yaklaşımlar. KÜ Tıp Fak Derg 2012;14.

22. Kurita H, Kurashina K, Kotani A. Clinical Effect of Full Covarage Occlusal Splint Theraphy For Spesific Temporomandibular Disorder Conditions and Symtoms, J. Prost Dent 1997; 78:506-510.
23. Glaros AG, Owais Z, Lausten L. Reduction inparafunctional activity: a potential mechanism forthe effectiveness of splint therapy, Journal of Oral Rehabilitation 2007; 34:97-104.

24. Conti PC, Santos CN, Kogawa EM, Conti CC, Arauzo CR. The treatment of painful temporomandibular joint clicking with oral splints: a randomized clinical trial. J Am Dent Assoc 2006; 137:1108-14.

25. Wassel RW, Adams N, Kelly PJ. The Treatment of Temporomandibular Disorders With Stabilizing Splints in General Dental Practice: One-Year Follow-Up.J Am Dent Assoc 2006; 137:1089-98.

26. Katsoulis J, Richter M. Efficacy of Specific Physiotherapy for Temporomandibular Joint Dysfunction of Muscular Origin.Rev Stomatol Chir Maxillofac. $2008 ; 109: 9-14$.

27.Pekince $K A$, Caglayan $F$, Pekince $A$. Imaging of masseter muscle spasms by ultrasonography: a preliminary study Oral Radiol 2020; 36:85-88.

28. Çebi AT. Ultrasonographic evaluation of masseter muscle thickness in patients with disk displacement with reduction. Oral Radiol 2019; 35:239-244.

29. Tetsuka M, Saga T, Nakamura M, Tabira Y, Kusukawa J, Yamaki K, et al. Relationship between masseter muscle form and occlusal supports of remaining teeth. Kurume Med J 2012; 59:5-15.

30. Sathasivasubramanian $S$, Venkatasai PM, Divyambika CV, Rupesh M, Jeffrey R, Nathera Jabeen NA, et al. Masseter muscle thickness in unilateral partial edentulism: an ultrasonographic study. J Clin Imaging Sci. 2017; 7:44.

31. Emshoff R, Bertram S. The Short-Term Effect of Stabilization-Type Splints on Local Cross-Sectional Dimensions of Muscles of the Head and Neck.J Prosthet Dent 1998; 80:457-61.

\section{Sorumlu Yazarın Yazışma Adresi}

Dr. Meltem Özden Yüce

Ege Üniversitesi

Diş Hekimliği Fakültesi

Ağız, Diş ve Çene Cerrahisi AD

Bornova, İzmir, Türkiye

Tel no: 0232-311-28-09

E-Posta adresi: meltemozdn@hotmail.com 